\title{
Fine plastic foil as backing for sputtered nickel targets
}

\author{
Anna Stolarz • Raimo Seppälä
}

Received: 1 July 2013/Published online: 2 August 2013

(c) The Author(s) 2013. This article is published with open access at Springerlink.com

\begin{abstract}
Targets of ${ }^{58} \mathrm{Ni}$ and ${ }^{60} \mathrm{Ni}$ with areal density between 71 and $105 \mu \mathrm{g} / \mathrm{cm}^{2}$ backed with polyimide foil of $35-40 \mu \mathrm{g} / \mathrm{cm}^{2}$ were prepared by sputtering with Ar ions produced by a home made sputtering device at the Target Laboratory, University of Jyväskylä. The efficiency of the procedure was about $20 \%$.
\end{abstract}

Keywords Nickel $\cdot$ Sputtering $\cdot \mathrm{Cu}$ and $\mathrm{C}$ backing . Polyimide foil

\section{Introduction}

Investigation of the distribution of the fusion-barrier height performed with ${ }^{20} \mathrm{Ne}^{9+}$ ions provided by the Warsaw Cyclotron at Heavy Ion Laboratory, University of Warsaw required the targets of nickel isotopes: 58, 60 and 61 [1]. The required targets should be $80-100 \mu \mathrm{g} / \mathrm{cm}^{2}$ thick with the target area of $15 \mathrm{~mm}$ in diameter and most preferably self-supporting although thin support by foils of light elements was acceptable as not disturbing the studied phenomena.

Preparation of self-supporting Ni targets in this thickness range is quite difficult. Although $\mathrm{Ni}$ layers of such thickness can be prepared in high vacuum by vapour deposition on substrate it is difficult to mount the produced foils to frame as $\mathrm{Ni}$ foils in this thickness range have a

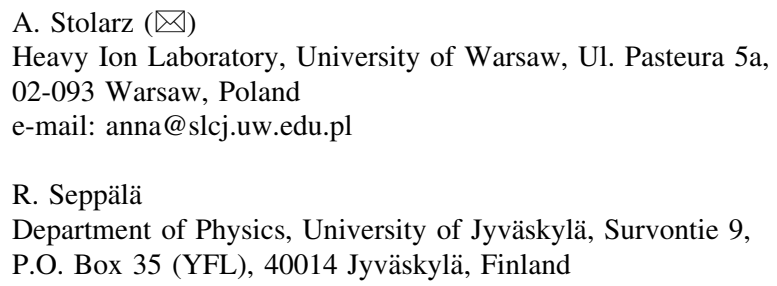

strong tendency to roll into tubes when self-supporting. This makes mounting the foils on the target frames when released from substrate very difficult if not impossible. To overcome this problem the thin $\mathrm{Ni}$ layer produced by vapour condensation or by sputtering, has to be, when still on the substrate, either additionally strengthened/stiffened by a support with low melting point removable under the beam or has to be produced on the backing which is removed after fixing the foils to the frame. Nevertheless, a method of producing $\mathrm{Ni}$ foils without the stresses responsible for this rolling effect has been recently reported in [2].

\section{Thin Ni layers production}

Sputtering device

Because of the nickel properties, i.e. its relatively high melting temperature and alloying with metals commonly used as the evaporation crucible nickel should be evaporated either by e-bombardment or e-gun heating or by sputtering.

Taking into account the minute amount of the $\mathrm{Ni}$ isotopes available for the target preparation and availability of the heating systems, the $\mathrm{Ni}$ foils were produced using the small home made sputtering device with sputtering voltage of $10 \mathrm{kV}$ and Ar ions as sputtering projectiles available at the Target Laboratory of Physics Department, University of Jyväskylä.

The cathode applied in this device is made of graphite with the cavity of $5 \mathrm{~mm}$ in diameter for the sputtered substance which allows the target production with minute amount of the material. A short adjustable distance of the sputtered material and the substrate assures the high efficiency of the material collection. The deposit thickness 
inhomogeneity that may be caused by this short distance is reduced by the substrate rotation [3].

\section{Ni deposition}

A pellet of compressed $\mathrm{Ni}$ powder was placed in the cavity of the graphite cathode (Fig. 1). The backing substrates were fixed to the rotating substrate holder placed at the distance of $2.3 \mathrm{~cm}$ from the Ni pellet. The thickness of the deposits was controlled by the time of sputtering process. The final thickness of the deposit was estimated using the weighing method. The targets were produced with the deposition rate varying between 1.3 and $2.5 \mu \mathrm{g} / \mathrm{cm}^{2} / \mathrm{min}$.

\section{On Cu substrate}

The attempt to produce a set of $\mathrm{Ni}$ foils by the procedure described in [2] ended with no positive outcome. The $\mathrm{Cu}$ foil of $8 \mu \mathrm{m}$ used as the backing was home prepared by rolling starting with $\mathrm{Cu}$ foils of $50 \mu \mathrm{m}$. Before applying as backing the $\mathrm{Cu}$ was annealed as recommended in [2] i.e. for $\sim 5$ min was heated in the vacuum at $\sim 600{ }^{\circ} \mathrm{C}$ by resistant heating. The Ni layer deposited on the $\mathrm{Cu}$ backing built up with the stress sufficient to bend the $\mathrm{Cu}$ backing (Fig. 2), nevertheless the Ni was released from the backing by $\mathrm{Cu}$ etching with trichloroacetic acid and ammonia [2, 4]. The released foils were, in majority of cases, rolling itself into tubes (Fig. 3) making the mounting them on the frames infeasible.

Fixing the foils to the frame before etching the copper backing as used for thicker Ni foils production by Arnison [4] gave no positive outcome either. The foils cracked either during the etching process (Fig. 4) or during the drying step.

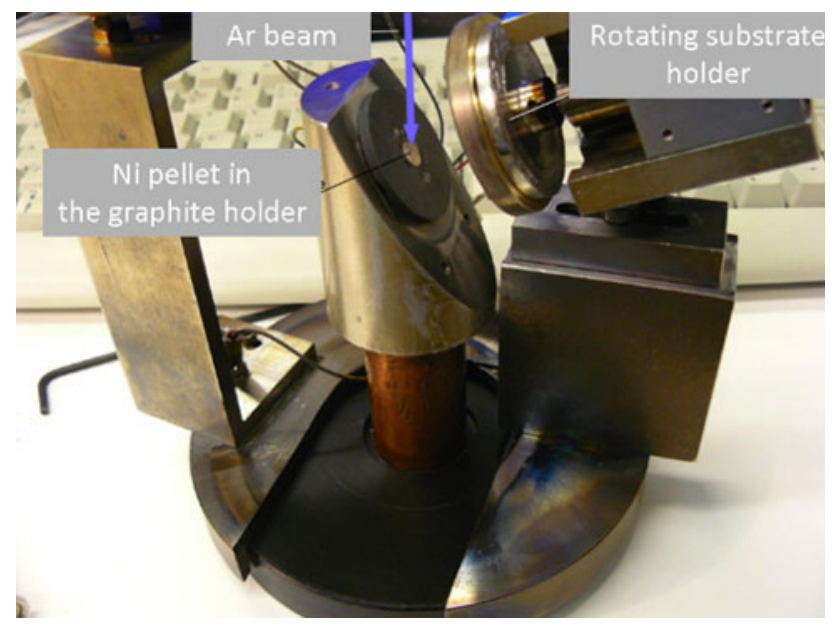

Fig. 1 The heart of the sputterer; to the left is the graphite cathode with small cavity for the sputtered material; the rotating substrate holder is on the right

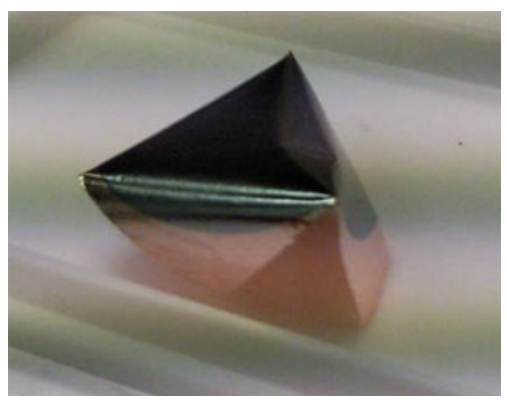

Fig. 2 The nat $\mathrm{Ni}$ layer deposited on the $8 \mu \mathrm{m} \mathrm{Cu}$ foil

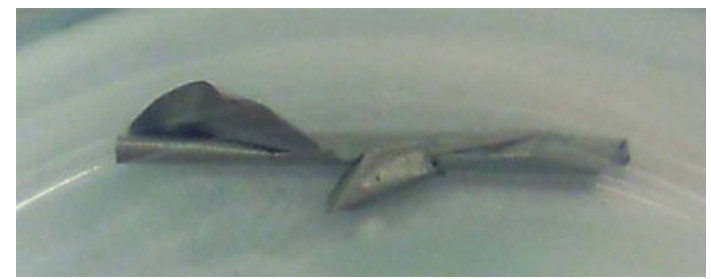

Fig. $3 \mathrm{Ni}$ foil made by sputtering on the $\mathrm{Cu}$ backing after etching the backing
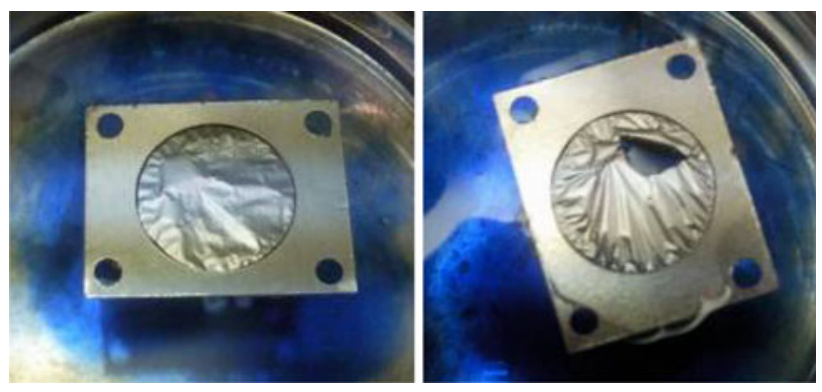

Fig. $4 \mathrm{Ni}$ foils deposited on the $\mathrm{Cu}$ backing during etching process

The approach to the deposition of the sputtered $\mathrm{Ni}$ on substrate heated during $\mathrm{Ni}$ vapour deposition as recommended by Gursky [5] was not feasible in the device used for Ni layer production.

\section{On low-Z backing}

Taking into account no reproducibility of the foils production by deposition on the $\mathrm{Cu}$ backing further etched to obtain the self-supported foil and the fact that required targets were allowed to be backed by support of low$Z$ elements an attempt of depositing the Ni layers on a thin $\left(10-12 \mu \mathrm{g} / \mathrm{cm}^{2}\right) \mathrm{C}$ foil was undertaken. It was not successful either. The $\mathrm{C}$ foil did not withstand bombardment by the sputtered $\mathrm{Ni}$ or the stress built up in the $\mathrm{Ni}$ foil during its deposition was too high. The frame after the sputtering was empty with only a few small scraps stuck to the substrate holder.

Finally targets for the experiment were prepared by nickel deposition on $\sim 35$ and $40 \mu \mathrm{g} / \mathrm{cm}^{2}$ polyimide foil 

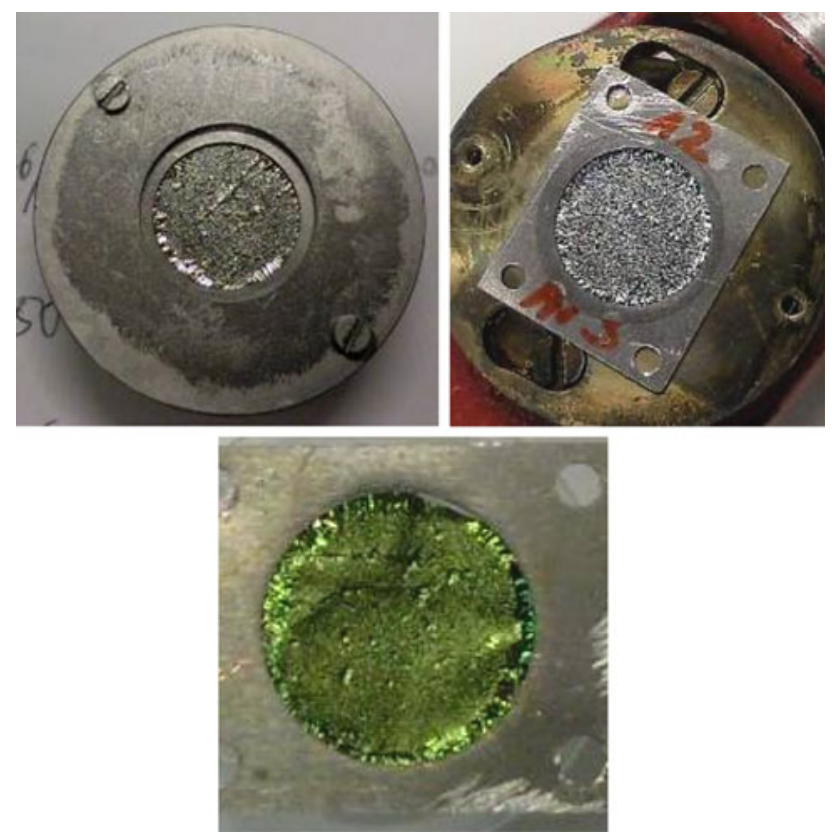

Fig. 5 Top left the Ni target in the holder of the sputtering device (from the Ni side). Top right the circle of the $\mathrm{Ni}$ (darker gray ring) on the frame guarantee the contact with frame to facilitate the heat transfer from the target material. Bottom the view of the target from the PIF side

(PIF) prepared in air or in argon [6]. The sputtering voltage applied in this process was $\sim 6.5 \mathrm{kV}$.

The PIF mounted to the frame was fixed to the rotating substrate holder using the mask, fixing the frame to the substrate and determining the size of the deposit (Fig. 5). Its aperture was $4 \mathrm{~mm}$ bigger than the aperture of the target frame. This was to assure a good contact of the Ni layer with target frame. It was aimed to enhance the dissipation of the heat deposited in the target by the bombarding beam.

The thickness of the deposit, as for deposition process on $\mathrm{Cu}$ was controlled by the time of sputtering process and the thickness of the completed deposit was estimated using the weighing method.

\section{Results}

Applying described procedure the foils of natural nickel with areal density of $110-160 \mu \mathrm{g} / \mathrm{cm}^{2}$ and isotopic nickel, 58 and 60 , with areal density of $71-115 \mu \mathrm{g} / \mathrm{cm}^{2}$ (Table 1 ) were produced with average material consumption amounting in $\sim 2.5 \mathrm{mg}$ per target.

The behaviour of each PIF type under the nickel 'projectiles' initially differed but an additional thermal treatment ( 15 min at $350{ }^{\circ} \mathrm{C}$ in the oven) of PIFs made both types of the foil usable as backing for Ni deposition by the sputtering technique.
Table 1 Isotopic targets prepared by Ni sputtering with $6.5 \mathrm{kV} \mathrm{Ar}$ ions

\begin{tabular}{llrl}
\hline & $\begin{array}{l}\text { Time } \\
(\mathrm{min}]\end{array}$ & $\begin{array}{c}\text { Thickness } \\
\left(\mu \mathrm{g} / \mathrm{cm}^{2}\right)\end{array}$ \\
\hline Ni-58: target label & & & \\
PIF 4q & 45 & 71.54 & PIF - melted \\
PIF 7s & 35 & 115.26 & \\
PIF 8s & 43.5 & 93.40 & Slightly damaged \\
PIF 9s & 45 & 103.34 & \\
& & 99.36 & \\
PIF 10s & 45 & & \\
PIF 11q & 80 & 102.54 & \\
Ni-60: target label & & 99.36 & \\
PIF 11s & 45 & 104.66 & Small cut on the edge \\
PIF 12s & 40 & 83.86 & \\
PIF 5q & 70 & 105.33 & \\
PIF 8q & 65.5 & & \\
PIF 9q (two runs) & $70+20$ & & \\
\hline
\end{tabular}

Table 2 Comparison of the thickness of the chosen Ni foils estimated by weighing and by $\alpha$ particles energy loss measurement

\begin{tabular}{llll}
\hline Targets & $\begin{array}{l}\text { PIF } \mu \mathrm{g} / \mathrm{cm}^{2} \\
\text { by } \alpha\end{array}$ & Target thickness $\left(\mu \mathrm{g} / \mathrm{cm}^{2}\right)$ \\
\cline { 3 - 4 } & & Ni by weighing & By $\alpha$ \\
\hline Ni 58 PIF 10s & 40 & 103.34 & $135,150,154,146$ \\
Ni 60 PIF 9q & 35 & 105.33 & 146,156 \\
\hline
\end{tabular}

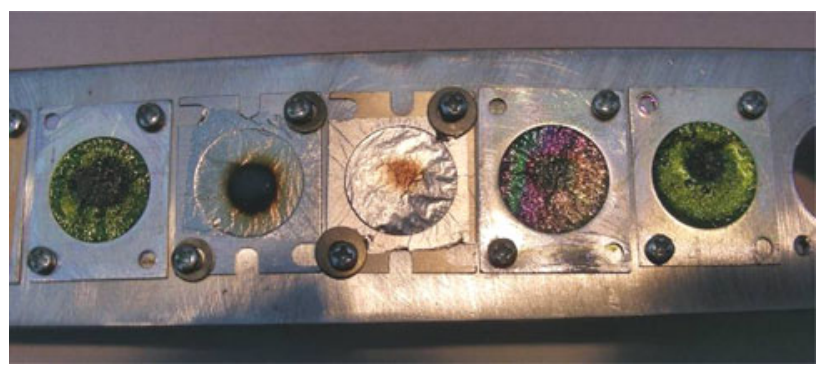

Fig. 6 The set of Ni targets supported by PIF (from the left positions $1,4,5)$ and self-supporting (positions 2, 3) after bombardment by the ${ }^{20} \mathrm{Ne}^{9+}$ beam of $50 \mathrm{MeV}$ with $30 \mathrm{nA}$ intensity

The thickness of a few randomly chosen targets was additionally determined with measurements of the alpha particles energy loss (Table 2). The obtained results confirmed the impact of the substrate rotation on the homogeneity of the deposit distribution (Fig. 6).

According to the report from the end users targets prepared by the method described here survived the bombardment by ${ }^{20} \mathrm{Ne}^{9+}$ ions beam of $\sim 50 \mathrm{MeV}$ with intensity 
of $30 \mathrm{nA}$. It confirms the suitability of the PIFs as backings for targets used in the beam of heavy ions.

Acknowledgments The polyimide foils used in these studies were prepared at IRMM (Institute for Reference Materials and Measurements, Geel, Belgium) for measurements of their life time under the beam and purity analysis performed in 2010 [6].

Open Access This article is distributed under the terms of the Creative Commons Attribution License which permits any use, distribution, and reproduction in any medium, provided the original author(s) and the source are credited.

\section{References}

1. Trzcińska A (2010) HIL Annual Report, p 35. http://www.slcj.uw. edu.pl/pl/reports/HIL-Report10.pdf

2. Lommel B, Hartmann W, Hübner A, Kindler B, Steiner J (2011) Nucl Instrum Methods A 655:44
3. Sletten G, Knudsen P (1972) Nucl Instrum Methods 102:459

4. Arnison GTJ (1967) Nucl Instrum Methods 53:357

5. Gursky JC (1977) Report LA-6850-C, p 198

6. Sibbens G, Luyckx K, Stolarz A, Jaskóła M, Korman A, Moens A, Eykens R, Sapundjiev D, Aregbe Y (2011) Nucl Instrum Methods A $655: 47$ 